\section{Failure of Agrobacterium radiobacter Strain K-84 to Control Crown Gallon Raspberry}

\author{
Thomas J. Burr, Cheryl L. Reid, and Barbara H. Katz \\ Department of Plant Pathology, New York State Agricultural Experiment \\ Station, Cornell University, Geneva, NY 14456
}

Maria Elisabetta Tagliati and Carlo Bazzi

Istituto di Patologia Vegetale, University of Bologna, 40126, Bologna, Italy

Deborah I. Breth

Cornell Cooperative Extension, P.O. Box 150, Albion, NY 14411-0150

Additional index words. Agrobacterium tumefaciens, biological control, agrocin, Rubus idaeus

\begin{abstract}
Agrobacterium radiobacter (Beijerinc and van Delden) Conn strain K-84 failed to control raspberry (Rubus idaeus L.) crown gall caused by A. tumefaciens (E.F. Smith and Townsend) Conn. Agrobacterium tumefaciens strains isolated from galls on plants that had been treated with K-84 were not sensitive to agrocin 84 in vitro. These strains were isolated from 'Titan' and 'Hilton' raspberry in New York state and from 'Himbo Queen' and 'Schönemann' raspberry in Italy. Almost all strains were identified as A. tumefaciens biovar 2. Raspberry crown gall was not controlled by K-84 in three field experiments in New York state. In two of the experiments, plants were produced by micropropagation and were known to be pathogen-free. The other plant source was shown to be contaminated with the pathogen before treatment with $\mathrm{K}-84$. Crown gall was not controlled either on raspberry in a greenhouse experiment or on Kalanchoe diagremintiana (Hamet. and Perrier) plants that were coinoculated with K-84 and strains of A. tumefaciens isolated from galls on raspberry.
\end{abstract}

Agrobacterium radiobacter strain $\mathrm{K}-84$ is a highly effective biological control of crown gall on certain plant species (Kerr, 1980). K84 produces a bacteriocin, agrocin 84 , that is an important factor contributing to its biological control activity (Kerr and Htay, 1974). The sensitivity of $A$. tumefaciens strains to agrocin 84 in vitro correlates well but not perfectly with biological control. Other factors, such as competition for binding sites, also may be associated with biological control (Cooksey and Moore, 1982). Sensitivity of specific strains of $A$. tumefaciens to agrocin 84 is encoded by determinants on the Ti plasmid (Eagler et al., 1975). Although crown gall control is highly effective on some host plants, such as stone fruit and nut trees, K-84 does not control crown gall on other hosts (Kerr and Panagopoulos, 1977).

Crown gall is an important disease of certain raspberry cultivars. Sule and Kollanyi (1977) reported that strain K-84 reduced crown gall severity on raspberry in Hungary but did not provide satisfactory control.

This paper reports the results of experiments to test the effectiveness of strain K-84 for controlling raspberry crown gall. Raspberry plants from two sources were used in

Received for publication 8 Feb. 1993. Accepted for publication 1 June 1993. The cost of publishing this paper was defrayed in part by the payment of page charges. Under postal regulations, this paper therefore must be hereby marked advertisement solely to indicate this fact. field and greenhouse experiments. These were 'Hilton', harvested in November from a field at nursery A, where crown gall was prevalent, and 'Titan', provided in May by Nourse Farms (South Deerfield, Mass.). The 'Titan' plants were micropropagated and subsequently grown in a greenhouse; thus, they were expected to be free of $A$. tumefaciens. To determine if either plant source was contaminated with $A$. tumefaciens, root samples from five to 10 plants were cut in small pieces; suspended in individual flasks in $250 \mathrm{ml}$ of sterile, distilled water; and shaken on a shaker for $1 \mathrm{~h}$. Serial dilutions then were plated on selective media for $A$. tumefaciens biovar 1 (Schroth et al., 1965 ) and biovar 2 (New and Kerr, 1971). Plates were incubated at $28 \mathrm{C}$ for 5 to 7 days and colonies resembling $A$. tumefaciens were subculture on potato dextrose agar (PDA) (Difco, Detroit). Strains resembling $A$. tumefaciens were selected from these isolation plates; 24 were taken from nursery A stock, and 12 from Nourse Farms stock.

Strains were tested for tumorigenicity in the greenhouse by inoculating sunflower (Helianthus annuus L.) stems. Bacterial growth from 48-h-old cultures on PDA was collected on the end of a sterile toothpick and placed on stems of 1-week-old sunflower plants. A wound was made through the bacterial cells into the sunflower stem with a sterile needle. Three inoculations were made on each sunflower stem, and at least five plants were inoculated per strain. Six strains from nursery A and none from Nourse Farms were pathogenic.
Field experiments were conducted with plants from nursery A at the same nursery and with plants from Nourse Farms at two grower sites in western New York. One site belonged to grower Becker and had been planted in 'Titan' raspberry, which had severe crown gall (Fig. 1A). The plants were removed from this field in Fall 1990, and the soil was prepared for the 1991 experiment. Immediately before planting, abundant galls were observed on roots that had overwintered in the soil. The second experiment site, which belonged to grower Kirby, was adjacent to a raspberry planting with a high incidence of crown gall, but no gall residues were apparent in the soil in which the experiment was conducted. The experiment at nursery A was planted in a field where raspberry had been planted but where crown gall had not been observed.

Inoculum for each biological control experiment was prepared from lawns of K-84 grown on $15-\mathrm{cm}$, disposable plastic petri dishes containing PDA. Suspending the growth from 10 dishes in 15 liters of distilled water resulted in a bacterial suspension of $\approx 10^{8}$ colony forming units $(\mathrm{cfu}) / \mathrm{ml}$. We determined inoculum concentrations by plating serial dilutions on PDA and counting colonies after $48 \mathrm{~h}$.

The raspberry roots and crowns were soaked in the K-84 suspension for $\geq 5$ min before being planted in the field. Each plant from Nourse Farms came in a small peat pot that was removed before the fibrous root system was soaked in the K-84 suspension. The 150 treated and 150 nontreated (control) plants were divided into two 75-plant replications in each field (Becker and Kirby) and were planted on 23 May. Plants from nursery A had been field-propagated and thus had woody root systems, which were treated with K-84 as above, The experiment at nursery A had 2476 treated and 1699 control plants. There were six replications of K-84-treated plants and four control replications, each replication had $\geq 400$ plants. Replications were completely randomized within the field. Treatments for nursery A were applied on 20 May. Control plants for all experiments were dipped in distilled water. Plants were irrigated and maintained by each grower for the experiment's duration.

To assess crown gall development, 20 Nourse Farms plants from each replication (40 per field site) in the Becker and Kirby fields were dug and observed in May, 1 year after planting. For the nursery A experiment, all of the treated and control plants were dug (since these were part of the nursery crop) and inspected for crown gall. Abundant crown gall developed on treated and nontreated plants in all experiments (Table 1). Most of the galls that developed on roots in the Becker and Kirby fields were on roots that had grown out from the initial plug of fibrous roots (Fig. 1B).

Because there was a high incidence of crown gall in all plots treated with K-84, it was necessary to determine if the pathogen strains present in the fields were sensitive to agrocin 84. Ten infected plant samples were collected from the Becker and Kirby sites, and 24 plants that had crown gall and were treated with K-84 were collected from the nursery A site. Isola- 


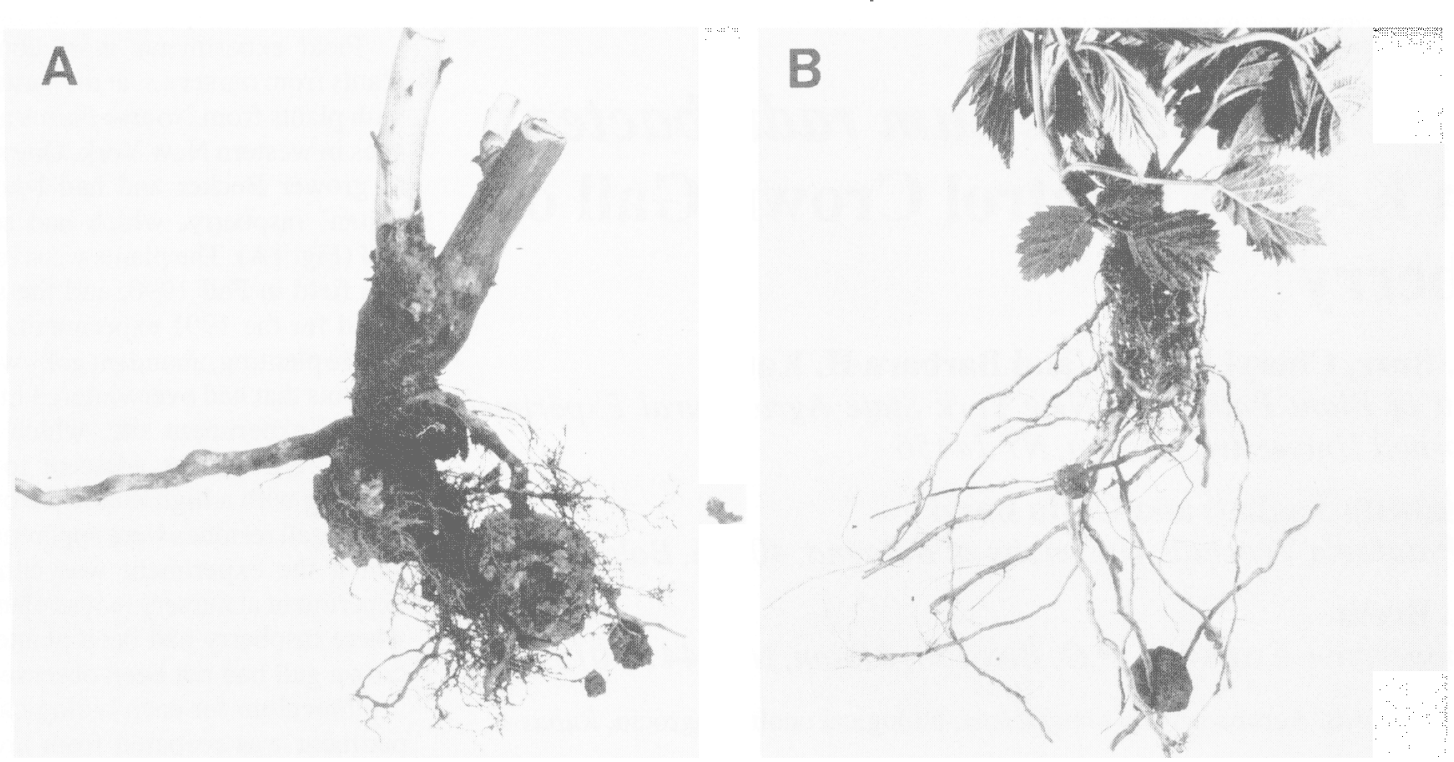

Fig. 1. (A) Typical crown gall on 'Titan' that was removed from the Becker site before the experiment was conducted in this field. (B) 'Titan' plant treated with K-84 and planted at the Becker site. Note remaining fibrous root ball on micropropagated plant and galls that developed on newly formed roots.

tions of A. tumefaciens were made by suspending pieces of fresh gall tissue in sterile, distilled water and plating on the selective media cited previously. Presumptive biovar identity of these strains was determined by the growth on selective media from which they were isolated and by testing for the production of 3ketolactose (Bernaerts and De Ley, 1963). Tumorigenicity was tested as described previously.

We also determined if $A$. tumefaciens strains isolated from galls on raspberry in Italy were similar to the strains from New York with regard to agrocin 84 sensitivity, biological control by K-84 in the greenhouse, and biovar classification. Samples of infected 'Himbo Queen' and 'Schönemann' were collected from infected fields at Pergine Valsugana and Capregheri, both in the Trento district of northern Italy. Forty-four Agrobacterium strains were isolated from tumors of both cultivars, and 22 were tumorigenic. All pathogenic strains belonged to biovar 2 .

To test the sensitivity of strains from New York and Italy to agrocin 84, a single streak of K-84 cells was made across a plate of mannitol glutamate medium (Cooksey and Moore, 1982), which is routinely used to bioassay agrocin 84 . After $48 \mathrm{~h}$ at $28 \mathrm{C}$, we stopped K84 growth by placing a filter paper saturated

Table 1. Effectiveness of strain K-84 for controlling crown gall on 'Titan' and 'Hilton' raspberry in field experiments.

\begin{tabular}{lccc}
\hline & & \multicolumn{2}{c}{$\begin{array}{c}\text { Plants with crown gall } \\
\text { (\%) }\end{array}$} \\
\cline { 3 - 4 } Site & Cultivar & Control & K-84-treated \\
\hline Becker & Titan & 63 & 46 \\
Kirby & Titan & 38 & 50 \\
Nursery A & Hilton & 26 & 24 \\
\hline
\end{tabular}

${ }^{2}$ For Becker and Kirby, 40 plants for each treatment were observed 1 year after treatment. For Nursery A, a total of 2486 treated and 1846 nontreated plants were harvested from the field and evaluated for crown gall. with chloroform in the lid of the glass petri dish and inverting the plate for $\approx 30 \mathrm{~min}$ to expose K-84 to the vapor. After the plates were aired in a fume hood, the K-84 growth was scraped from the plates with a rubber spatula. Sensitivity of A. tumefaciens strains to the agrocin 84 that had diffused into the medium was determined by streaking them across the plate perpendicular to the K-84 streak. Sensitivity is observed as a zone of growth inhibition at the K-84 streak (Fig. 2). Known agrocin 84-sensitive (CG922) and insensitive (R-3) strains were used as positive and negative controls, respectively. Only three of 32 tumorigenic strains from the Becker and Kirby sites (all biovar2) were sensitive to agrocin 84 . None of the Italian strains was sensitive to agrocin 84 . All tests were repeated at least once, with identical results each time.

We also conducted greenhouse experiments to test biological control by K-84. One experiment was performed on 'Hilton', from nursery $\mathrm{A}$, that had been shown to carry a resident population of A. tumefaciens. The K-84 inocu- lum was grown on PDA as in the field experiments, and raspberry plants were dipped into the suspension for $5 \mathrm{~min}$ before being planted in Cornell potting mixture (Boodley and Sheldrake, 1977). Thirty-six plants were treated with $\mathrm{K}-84$, and 37 were dipped in water as controls. Plants were removed after 2 months, and the incidence of crown gall was recorded. The experiment was repeated once, and K-84 did not control crown gall in either experiment. When the results from both experiments were averaged, $9 \%$ of the controls and $24 \%$ of the K-84-treated plants had detectable crown gall.

Plants of Kalanchoe diagremintiana were inoculated with eight (three agrocin-sensitive) of the 32 tumorigenic strains that were isolated from the Becker and Kirby fields and with 15 strains from Italy. Bacteria were grown for 48 $\mathrm{h}$ at $28 \mathrm{C}$ on PDA. Suspensions of bacterial cells were made to an optical density of 0.1 using a spectrophotometer (equal to $\approx 10^{8} \mathrm{cfu} /$ $\mathrm{ml}$ ). Equal volumes and concentrations of $\mathrm{K}$ 84 and pathogen were mixed and $10-\mu l$ drops

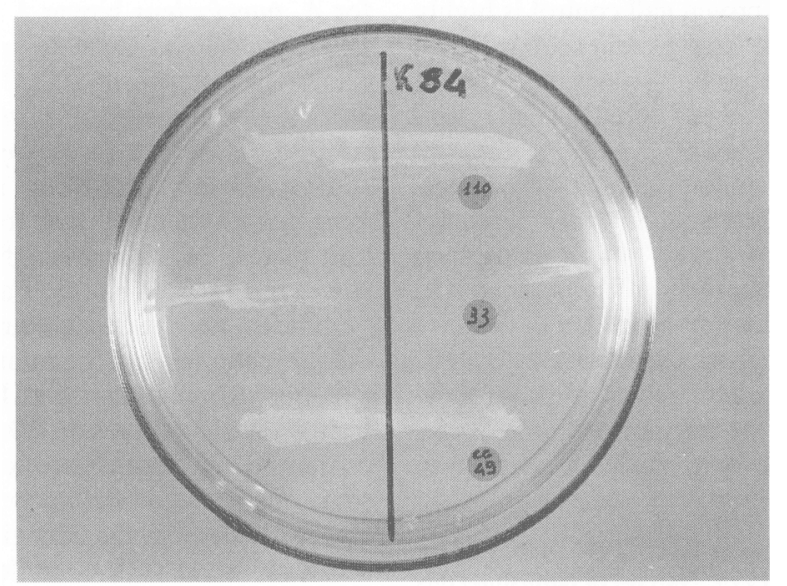

Fig. 2. Insensitivity of A. tumefaciens strains from raspberry to agrocin 84 . The center streak represents a strain that is sensitive to agrocin 84 . The other two strains are not sensitive. This test was conducted as described in the text. 


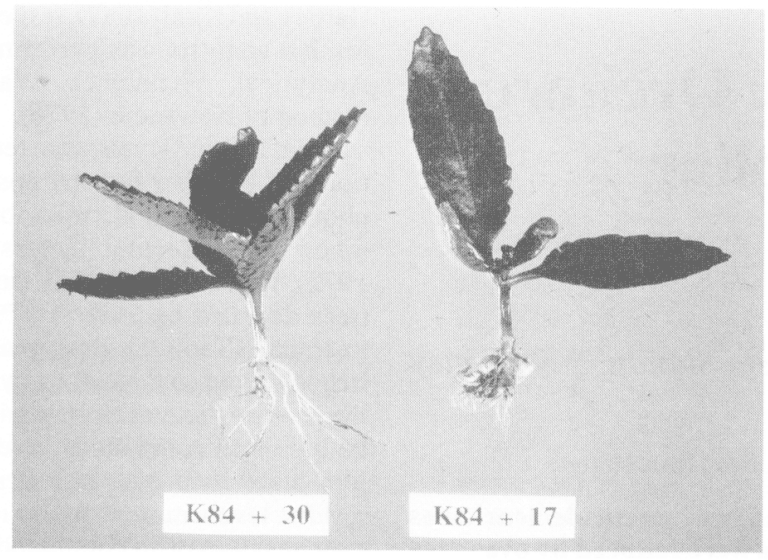

Fig. 3. Coinoculation with K-84 and Agrobacterium tumefaciens strain 30 (strain from the Becker farm that is sensitive to agrocin 84) results in disease control on Kalanchoe diagremintiana, and coinoculation of K-84 and $A$. tumefaciens strain 17 (strain from the Becker farm that is insensitive to agrocin 84 ) does not control crown gall.

of the resulting suspensions were placed at wound sites (made with a sterile pin) on plant crowns. Three plants were inoculated for each K-84-pathogen combination. In a second experiment, K-84 was applied to the wound sites $\approx 30$ min before inoculation with the pathogen. The plants were checked for galls 3 weeks after inoculation. Strain CG922 (known to be controlled by K-84) was used as a positive control, and strain CG936 (art insensitive strain) as a negative control. All experiments were repeated once.

Crown gall developed on $K$. diagremintiana plants coinoculated with K-84 and all but two of the strains from New York (Fig. 3). These two strains were sensitive to agrocin 84 in vitro. None of the 15 Italian strains were controlled. Galls failed to develop on plants inoculated with K-84 and CG922 but developed on plants with K-84 and CG936. No difference in control was observed between the coinoculation and preinoculation with $\mathrm{K}$ 84 and CG936.

Our experiments have demonstrated that K-84 failed to control raspberry crown gall at the field experiment locations in New York. The only other published report on the use of
K-84 on raspberry concluded that it suppressed crown gall but not to a commercially acceptable level and that $A$. tumefaciens strains recovered from raspberry were not sensitive to agrocin 84 (Sule and Kollanyi, 1977; Stale, personal communication). A major factor in the biological control activity of K-84 is the production of agrocin 84 . Almost all of the $A$. tumefaciens strains that were isolated from two raspberry cultivars in the three New York experiments and from two other cultivars of crown gall-infected raspberry from Italy were resistant to agrocin 84 . These data suggest that the resistance of $A$. tumefaciens strains from raspberry to agrocin 84 may be widespread and could lead to failure of biological control. Control failure also may be related to the K-84 concentration used. It is generally assumed that a ratio of $1 \mathrm{~K}-84: 1$ pathogen is adequate for disease control. Since population levels of field inoculum were unknown, higher concentrations of K-84 might have been more effective. Also, if plants had been inoculated with K-84 for a longer period before being planted in the field, a greater level of control might possibly have been achieved.

The planting material obtained from nurs- ery A and subsequently used in field and greenhouse experiments was found to be contaminated with A. tumefaciens. Because K-84 will not eradicate infections, the failure of $\mathrm{K}$ 84 to control crown gall in these experiments was not surprising. In contrast, the Nourse Farms planting material was free of $A$. tumefaciens, but K-84 still failed to control crown gall on these plants when they were planted in infested soils. Therefore, the inability of K-84 to control crown gallon raspberry appears to be associated with the insensitivity to agrocin 84 of the A. tumefaciens strains that infect raspberry. Other factors, such as competition of strains for binding sites on plant cells, also may be involved.

\section{Literature Cited}

Bernaerts, M.J. and J. De Ley. 1963. A biochemical test for crown gall bacteria. Nature (London) 197:406-407.

Boodley, J.W. and R. Sheldrake, Jr. 1977. Cornell peat-like mixes for commercial plant growing. New York State College Agr. Life Sci., Info. Bul. 43.

Cooksey, D.A. and L.W. Moore. 1982. Biological control of crown gall with an agrocin mutant of Agrobacterium radiobacter. Phytopathology 72:919-921.

Eagler, G., M. Holsters, M. van Montagu, and J. Schell. 1975. Agrocin 84 sensitivity: A plasmid determined property in Agrobacterium tumefaciens. Mol. Gen. Genet. 138:345-349.

Kerr, A. 1980. Biological control of crown gall through production of agrocin 84 . Plant Dis. 64:25-30.

Kerr, A. and K. Htay. 1974. Biological control of crown gall through bacteriocin production. Physiol. Plant Pathol. 4:37-44.

Kerr, A. and C.G. Panagopoulos. 1977. Biotypes of Agrobacterium radiobacter var. tumefaciens and their biological control. Phytopathol. Zeitschrift 90:172-179.

New, P.B. and A. Kerr. 1971. A selective medium for Agrobacterium radiobacter biotype 2. J. Applied Bacteriology 34:233-236.

Schroth, M.N., J.P. Thompson, and D.C. Hildebrand. 1965. Isolation of the Agrobacterium tumefaciens $-A$. radiobacter group from soil. Phytopathology 55:645-647.

Sule, S. and L. Kollanyi. 1977. Biological control of agrobacterium crown gall on raspberry. Növényvédelem 13:241-244. 